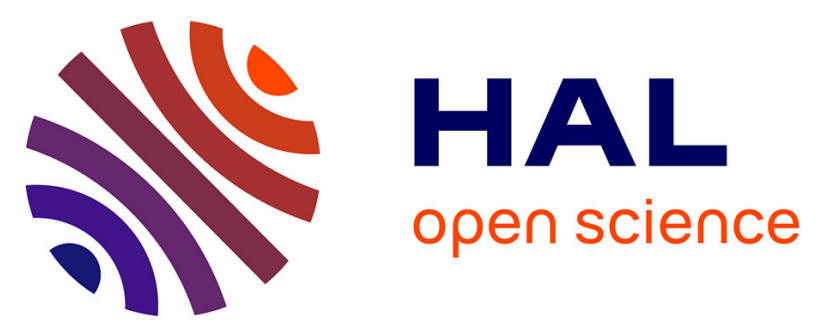

\title{
A Hybrid Anti-islanding Method for Inverter-Based Distributed Generation
}

Ebrahim Rokrok, Miadreza Shafie-Khah, Hamid Reza Karshenas, Esmail

Rokrok, João Catalão

\section{- To cite this version:}

Ebrahim Rokrok, Miadreza Shafie-Khah, Hamid Reza Karshenas, Esmail Rokrok, João Catalão. A Hybrid Anti-islanding Method for Inverter-Based Distributed Generation. 8th Doctoral Conference on Computing, Electrical and Industrial Systems (DoCEIS), May 2017, Costa de Caparica, Portugal. pp.259-266, 10.1007/978-3-319-56077-9_25 . hal-01629588

\section{HAL Id: hal-01629588 \\ https://hal.inria.fr/hal-01629588}

Submitted on 6 Nov 2017

HAL is a multi-disciplinary open access archive for the deposit and dissemination of scientific research documents, whether they are published or not. The documents may come from teaching and research institutions in France or abroad, or from public or private research centers.
L'archive ouverte pluridisciplinaire HAL, est destinée au dépôt et à la diffusion de documents scientifiques de niveau recherche, publiés ou non, émanant des établissements d'enseignement et de recherche français ou étrangers, des laboratoires publics ou privés.

\section{(c)(1)}

Distributed under a Creative Commons Attribution| 4.0 International License 


\title{
A Hybrid Anti-Islanding Method for Inverter-Based Distributed Generation
}

\author{
Ebrahim Rokrok ${ }^{1}$, Miadreza Shafie-khah ${ }^{1}$, Hamid Reza Karshenas², Esmail Rokrok ${ }^{3}$ \\ and João P.S. Catalão ${ }^{1,4,5}$ \\ ${ }^{1}$ C-MAST, University of Beira Interior, Covilhã 6201-001, Portugal \\ ${ }^{2}$ Isfahan University of Technology, Isfahan, Iran \\ ${ }^{3}$ University of Lorestan, Khorram Abad, Iran \\ ${ }^{4}$ INESC TEC and the Faculty of Engineering of the University of Porto, Porto 4200-465 \\ ${ }^{5}$ INESC-ID, Instituto Superior Técnico, University of Lisbon, Lisbon 1049-001, Portugal \\ ebrahim.rokrok@ubi.pt; miadreza@ubi.pt; karshen@cc.iut.ac.ir; rokrok.e@lu.ac.ir; \\ catalao@fe.up.pt
}

\begin{abstract}
Nowadays, high penetration of Distributed Generations (DG)s in power systems caused some protection issues. One of these issues is unintentional islanding. As regards IEEE 1547 standard, this situation must be recognized immediately, and DG must be separated from the load in less than 2 seconds. In this paper, to detection of islanding in an inverter-based distributed generation, a new hybrid method with high performance is proposed. In the proposed method, a primary detection of islanding is conducted by measuring the voltage harmonic distortion at the Point of Common Coupling (PCC), as well as comparing the variations to a specified threshold level. After this primary detection, a temporary reactive current signal is injected to the PCC by the inverter of DG, and its terminal voltage and frequency are measured. In the case of deviation of voltage or frequency from permissible range, definitive detection of islanding is determined. Simulation results indicate the efficiency and accuracy of the proposed detection method in different circumstances, especially for loads with the different quality factors.
\end{abstract}

Keywords: inverter-based distributed generation, islanding, non-detection zone, quality factor, total harmonic distortion.

\section{Introduction}

Due to the technical, economic and environmental advantages, integration of distributed generation units to power systems is growing increasingly. It seems that in the future, we will face with complex grids with a significant number of DGs [1].

In this regard, analysis of the issues and problems related to the connection of DGs is very important. One of these issues is unintentional islanding. Unintentional islanding happens when the switch of grid side is disconnected without a prior plan and in an unforeseen way, and subsequently, the DG has to feed the local loads alone.

According to IEEE 929-1988 standard, the DG must be disconnected immediately from the load once it islanded [2]. So, it is crucial to immediately detect islanding state and then separate the DG from the load. 
Generally, there is two main categories for detection methods: 1) local methods 2) remote methods. Local methods are classified to passive methods, active methods and hybrid methods. Remote methods are also divided into two general methods: at the utility level and communication-based methods.

In passive methods, the detection procedure is based on the measurement of variables such as frequency, voltage amplitude and harmonic distortion at the PCC. Passive techniques are low cost and have short operating time. These methods have no effect on grid's power quality. Various passive methods including 1- Voltage and frequency protection [3], 2- voltage and current harmonics detection [4], 3- Voltage phase jump detection [5], 4- Comparing the rate of change of frequency [6], 5Voltage unbalance [7], 6- Output power change rate [4], 7- Rate of change of frequency over power [8] have been studied. The main problem of these methods is that they have Non-Detection Zones (NDZs). NDZ is a region in which the islanding detection technique cannot detect islanding state [9]. This limitation of passive schemes is solved by using active schemes.

The main idea of an active scheme is that when a DG is islanded, a small disturbance will lead to a substantial change in system parameters, while the change are small when the DG is connected to the grid [10]. The active methods including: 1Impedance measurement [6], 2- Detection of impedance at specific frequency [6], 3Slip mode frequency shift [6], 4- Frequency bias or active frequency drift [6], 5Sandia frequency and voltage shift [11], 6- Frequency jump [6] can be noticed. Active methods have small NDZ. Instead, they have longer operating time than passive methods and have a negative effect on grid's power quality [9].

For a more accurate detection of islanding, the hybrid methods (both active and passive method) are used. These methods take advantage of the two-stage detection process. First, a passive method can be used as the primary diagnoses. After that, an active method is applied as the passive scheme became suspects to the islanding [12]. Hybrid methods including 1- Method based on voltage unbalance and positive feedback, 2- Method based on the shift of the voltage and reactive power $[4,10]$ can be cited.

In this paper, a hybrid detection method with high accuracy is proposed to detect the islanding state in an inverter-based DG. In this method, the primary detection is done by measuring the voltage harmonic distortion at the PCC and comparing its variation with a threshold level. Then, for a definitive detection of islanding, a reactive current signal is injected by the inverter of the DG to the PCC, and its voltage and frequency are measured. If the deviation of voltage and frequency passes the allowable limits, islanding is detected. Simulation results indicate the efficiency of the suggested method in different conditions.

\section{Relationship to Smart Systems}

The environmental issues besides increasing concern for traditional energy resources lead to increasing concentrations on distributed generation based on renewables. The grow of DG penetration level in the future smart grids leads to increasing need for high-performance anti-islanding protection methods [12]. Therefore, anti-islanding 
protection is so important that specific capabilities and specifications for antiislanding are required in the countries with a developed power grid system [13].

To connect the DGs to the grid, there are some conditions that must be considered. Standard institutions have published these conditions. On of the very significant conditions which are required to distributed generators is detecting the islanding state.

Unintentional islanding, because of loss of synchronism, can have undesirable effects on power system stability [14]. It is likely to damage the electrical appliances and equipment in the island. It is also dangerous for personnel or people. So, in modern smart grids, it is necessary to use effective and reliable methods to detect islanding conditions [15]. Numerous methods have been proposed to detect unintentional islanding so far. These methods are different in terms of cost, efficiency, execution speed and power quality issues. This paper, proposes an effective antiislanding detection method to the goal of reliable operation in future smart grids.

\section{Islanding Detection by Reactive Current Injection}

Figure 1 depicts the inverter-based DG and the local load at the PCC. When islanding occurs, the Circuit Breaker (CB) opens, and DG alone feeds the local load.

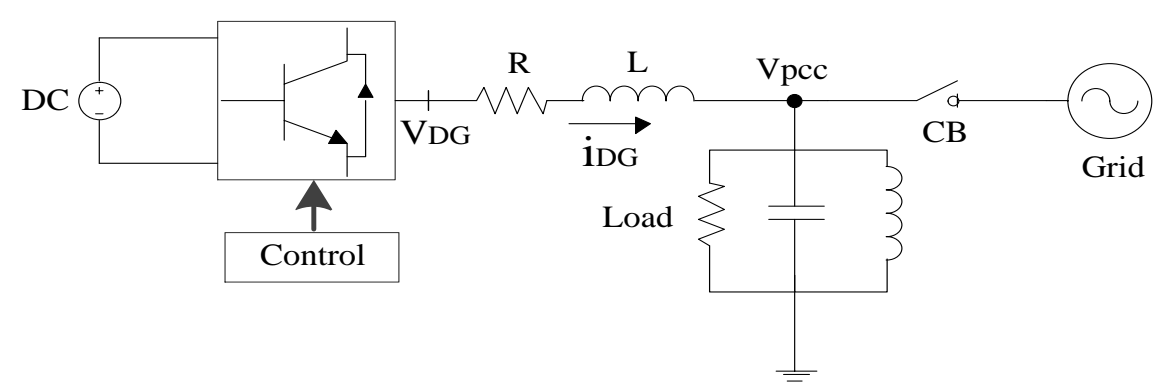

Fig. 1. DG with the local load connected to the grid.

The basis of islanding detection in reactive current injection method is making the reactive flow component in DG's output current through the control system and measuring the frequency and voltage at the PCC. To this end, a reactive triangular current signal with the frequency of $20 \mathrm{~Hz}$ can be used. The amplitude of this signal is considered as $10 \%$ of DG's rated current.

The voltage and frequency deviation lay outside of the standard ranges if the local load and DG's output power is not matched with each other. In this case, islanding can be diagnoses easily by voltage and frequency relays. However, if the DG's output power matches with the local load, frequency and voltage deviation are so small that relays can't detect islanding. In this case, injection of reactive current causes the frequency or voltage will be outside of the standard ranges and islanding is detected by voltage and frequency relays. 


\section{Proposed Method}

For improving power quality in reactive current injection method, it can be combined with a passive scheme. To detect islanding, first the passive scheme is used, and if it suspects of islanding, reactive current is injected. The reactive current injection will continue for a short time. If voltage or frequency was out of range during this period, the islanding has been detected, and DG will be separated. Otherwise injecting reactive current is interrupted and passive method is re-applied. So, DG does not have to inject reactive current continuously, and thus power quality is improved.

The passive method that used in this paper is measuring of the voltage Total Harmonic Distortion (THD) at the PCC. In the control system of inverter, the d-q components of the voltage are available and the voltage THD is obtained from these components [16].

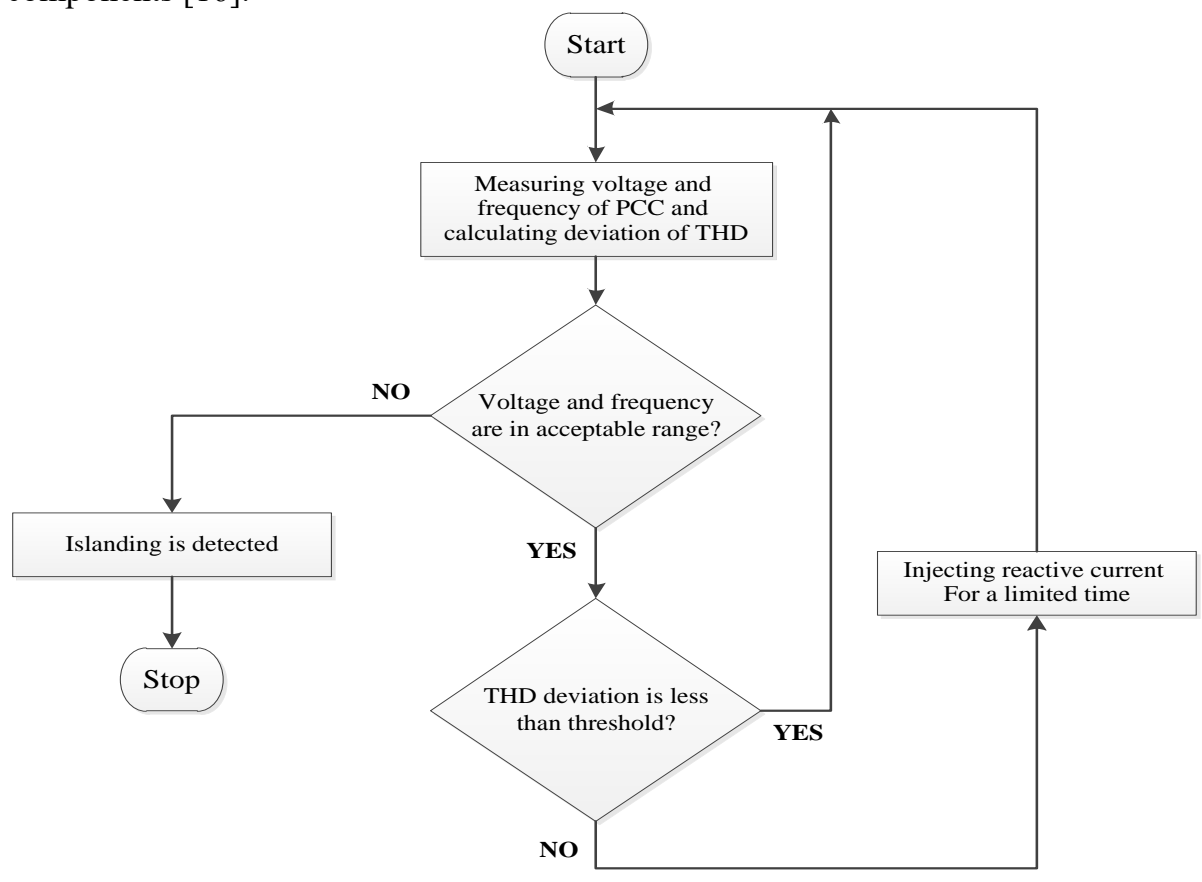

Fig. 2. Islanding detection by suggested method

In the suggested technique, voltage THD is sampled and is stored. The number of samples is fixed, and by adding a new sample in every cycle, the oldest sample is discarded. An average of samples is calculated by a moving window. The new sample will be compared with the average of previous samples. If the difference between these two is greater than a defined threshold level, the primary diagnosis of islanding is made, and then DG injects the reactive current. The flowchart of Figure 2 shows islanding detection procedure by proposed method. 


\section{Simulation Results}

To demonstrate the usefulness of the suggested method, a DG is connected to the local load and the utility grid (Fig. 1) is simulated in the Matlab-Simulink. The inverter is controlled in the PQ control mode. The modeling detail is presented in [3]. The characteristics of load, system and DG are specified in table 1.

Table 1. Test system characteristics.

\begin{tabular}{l|l|l}
\hline \multirow{3}{*}{ Grid } & Nominal voltage & $381 \mathrm{~V}$ \\
\cline { 2 - 3 } & Frequency & $60 \mathrm{~Hz}$ \\
\hline \multirow{4}{*}{ DG } & Rated power & $60 \mathrm{~kW}$ \\
\cline { 2 - 3 } & Rated voltage & $381 \mathrm{~V}$ \\
\cline { 2 - 3 } & Switching frequency & $5 \mathrm{kHz}$ \\
\cline { 2 - 3 } & DC link & $800 \mathrm{~V}$ \\
\cline { 2 - 3 } & Coupling reactance & $2.5 \mathrm{mH}$ \\
\hline \multirow{2}{*}{ Load } & High-quality factor & $\mathrm{Q}=2.3$ \\
\cline { 2 - 3 } & Low-quality factor & $\mathrm{Q}=0.2$ \\
\hline
\end{tabular}

Simulations results are given for three different states. In these simulations, the DG's output power is considered equal to the local load. In the other words, the worst loading conditions are considered. According to IEEE 929-2000 standard, allowable range of frequency is $59.3 \mathrm{~Hz}<\mathrm{f}_{\text {pcc }}<60.5 \mathrm{~Hz}$ and allowable voltage range is 0.88 p.u. $<V_{\mathrm{pcc}}<1.1$ p.u. that by taking effective amount $220 \mathrm{~V}$ for phase voltage, it will be $193.6 \mathrm{~V}<\mathrm{V}_{\mathrm{pcc}}<242 \mathrm{~V}$.

\subsection{Case 1: Islanding Detection by Permanent Injection of Reactive Current for a Load with a Low-Quality Factor:}

In the case of accordance of DG's real power and loads with high/low-quality factor, islanding is not detected based on voltage and frequency measurement. So, the triangular reactive current with the frequency of $20 \mathrm{~Hz}$ and the amplitude of $10 \%$ of the DG rated current is continuously injected. Figure 3 shows the frequency and voltage quantity at PCC. At $\mathrm{t}=1(\mathrm{~s})$, the grid is disconnected, and islanding occurs.

As can be seen from these figures, frequency and voltage range are excluded from standard limit and islanding is detected. For the high-quality factor load, by decreasing the amplitude of injected reactive current up to $5 \%$ of the DG nominal current, detection can be done. But in any case, continuous injection of reactive current can reduce the system's power quality. 

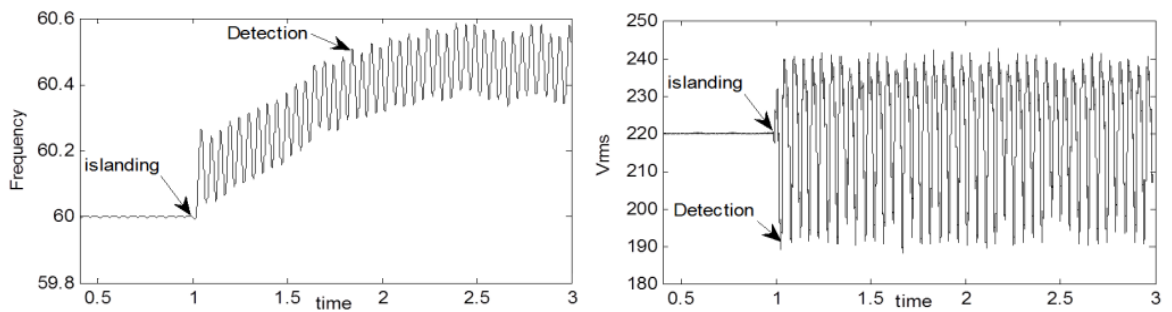

Fig. 3. Voltage and frequency of PCC with permanent reactive injection for low-quality load

\subsection{Case 2: Evaluation of Islanding Detection with the Proposed Method:}

In figure 4, the average of THD of the voltage at PCC (average of 50 samples with 1 $\mathrm{kHz}$ sampling rate) and reactive current injected are depicted. At $\mathrm{t}=1(\mathrm{~s})$, the grid is disconnected, and islanding happens. At $\mathrm{t}=1.02(\mathrm{~s})$, THD changes will be higher than the threshold level $(3 \%)$, and the primary detection is done. Then the reactive current is injected. Figure 5 illustrates the voltage and frequency of PCC . It is observed that the voltage is out of range in a short time and islanding is detected. Current injection is stopped, and DG must be separated.
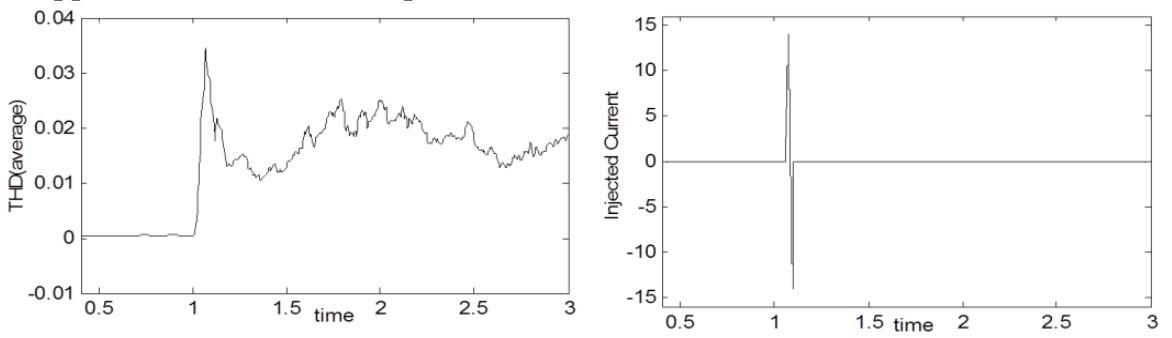

Fig. 4. The average of THD of the voltage at PCC and injected reactive current
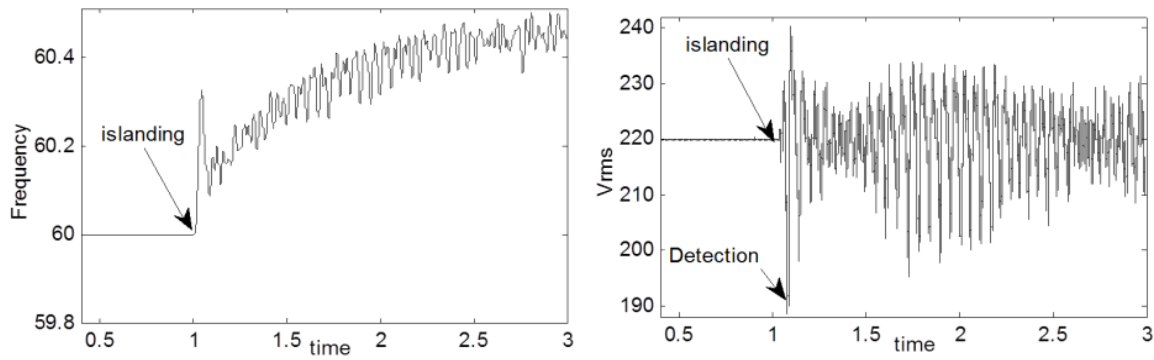

Fig. 5. Voltage and frequency of PCC with temporary reactive injection for low-quality load

\subsection{Case 3: Non-Linear Load Switching:}

Non-linear loads, such as rectifiers, when connecting to PCC can cause changes in the voltage THD levels. In this simulation, at the moment $t=1(\mathrm{~s})$, a rectifier as a non- 
linear load is connected to PCC. THD changes are more than the threshold, and the primary detection of islanding is done. Then the reactive current is injected within 0.1 s (Figure 6). Figure 7 shows the frequency and voltage of PCC. It is observed that the voltage and frequency will not be out of allowable range. So DG is not islanded, and injection of reactive current will be stopped, and DG will continue to work.
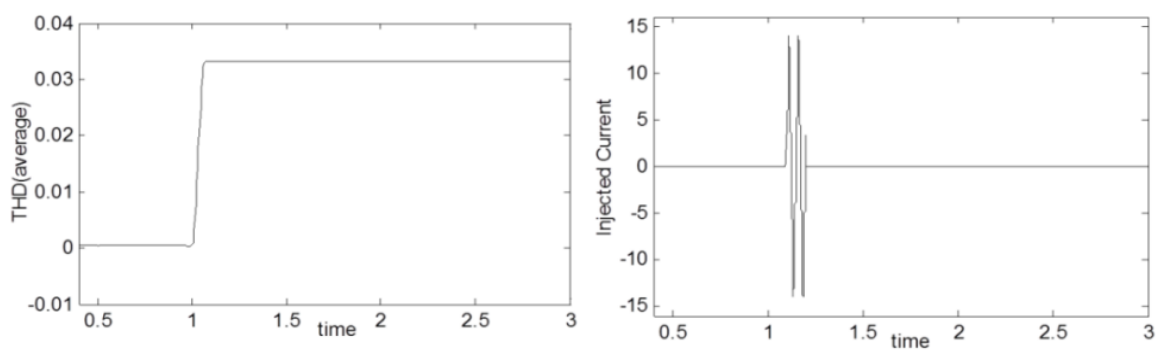

Fig. 6. The average of THD of the voltage at PCC and injected reactive current.
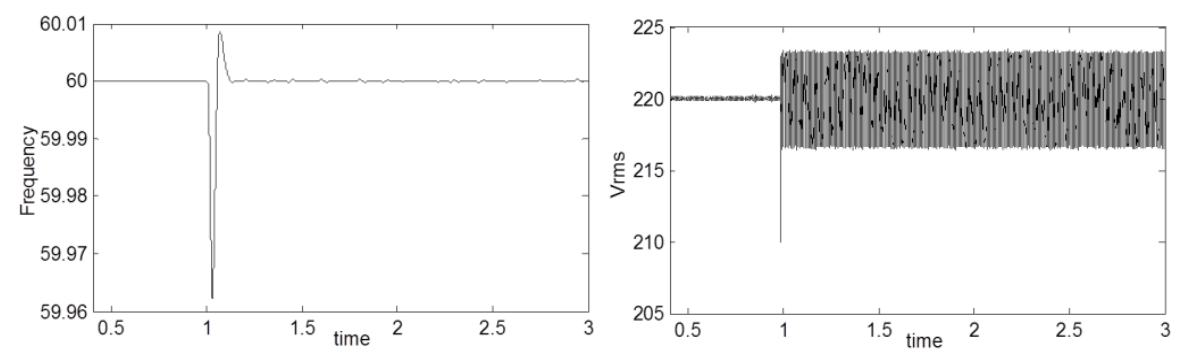

Fig. 7. Voltage and frequency of PCC with temporary reactive injection for low-quality load.

\section{Conclusions}

In connection of DGs to power systems, unintentional islanding is one of the important problems that must be investigated. According to existing standards, this phenomenon should be immediately diagnosed. Grid and load characteristics can determine factors for selection of an islanding detection method. This paper suggested a hybrid approach to detection of islanding. In the beginning, the primary detection of the islanding was done by measuring the THD of voltage at the PCC and comparing its variation to a threshold level. After confirmation of primary detection, for definite detection, a reactive current signal was injected to the PCC and voltage, and frequency deviations were measured at this point. Simulation results showed the efficiency of the suggested technique especially for the loads with non equal quality factor. Likewise, the switching of non-linear loads and correct diagnosis of nonislanding was simulated.

Acknowledgment. This work was supported by FEDER funds through COMPETE 2020 and by Portuguese funds through FCT, under Projects SAICT-PAC/0004/2015 - 
POCI-01-0145-FEDER-016434,

POCI-01-0145-FEDER-006961, UID/EEA/50014/2013, UID/CEC/50021/2013, and UID/EMS/00151/2013. Also, the research leading to these results has received funding from the EU Seventh Framework Programme FP7/2007-2013 under grant agreement no. 309048.

\section{References}

1. S. Shrivastava, S. Jain, and R. K. Nema. "A Proposed Hybrid Method for Islanding Detection." International J of Engineering Science and Technology 2.5 (2010): 813-817.

2. IEEE Std. 929-2000, IEEE Recommended Practice for Utility Interface of Photovoltaic(PV) Systems, Sponsored by IEEE Standards Coordinating Committee 32 on Photovoltaic, IEEE Std. 929-2000, Published by the IEEE, New York, NY, Apr.2000.

3. Bae, Byung-Yeol, et al. "Islanding detection method for inverter-based distributed generation systems using a signal cross-correlation scheme." Journal of Power Electronics 10.6 (2010): 762-768.

4. Mahat, Pukar, Zhe Chen, and Birgitte Bak-Jensen. "Review of islanding detection methods for distributed generation." Electric Utility Deregulation and Restructuring and Power Technologies, 2008. DRPT 2008. Third International Conference on. IEEE, 2008.

5. Aljankawey, A. S., et al. "Passive method-based islanding detection of renewable-based distributed generation: the issues." Electric Power and Energy Conference (EPEC), 2010 IEEE. IEEE, 2010.

6. Bower, Ward, and Michael Ropp. "Evaluation of islanding detection methods for utilityinteractive inverters in photovoltaic systems." Sandia report SAND3591 (2002): 2002.

7. Jang, Sung-Il, and Kwang-Ho Kim. "An islanding detection method for distributed generations using voltage unbalance and total harmonic distortion of current." IEEE transactions on power delivery 19.2 (2004): 745-752.

8. Pai, Fu-Sheng, and Shyh-Jier Huang. "A detection algorithm for islanding-prevention of dispersed consumer-owned storage and generating units." IEEE Transactions on Energy Conversion 16.4 (2001): 346-351.

9. Etxegarai, A., P. Eguía, and I. Zamora. "Analysis of remote islanding detection methods for distributed resources." Int. Conf. Renew. Energies Power Quality. 2011.

10.Chandrakar, Ch, Sh., Dewani, B., Chandrakar, D., "An Assessment of Distributed Generation Islanding Detection Methods", International Journal of Advances in Engineering \& Technology, Vol. 5, Issue 1, pp. 218-226, Nov. 2012.

11.Kunte, Rohit S., and Wenzhong Gao. "Comparison and review of islanding detection techniques for distributed energy resources." Power Symposium. 2008.

12.Teoh, Wei Yee, and Chee Wei Tan. "An overview of islanding detection methods in photovoltaic systems." World Academy of Science, Engineering and Technology 58 (2011): 674-682.

13.Boroojeni, Kianoosh G., M. Hadi Amini, and S. S. Iyengar. "Overview of the Security and Privacy Issues in Smart Grids." Smart Grids: Security and Privacy Issues. Springer International Publishing, 2017. 1-16.

14.Bahrami, Shahab, and Aras Sheikhi. "From demand response in smart grid toward integrated demand response in smart energy hub." IEEE Trans. on Smart Grid 7.2 (2016): 650-658.

15.Arasteh, H., et al. "Iot-based smart cities: A survey." Environment and Electrical Engineering (EEEIC), 2016 IEEE 16th International Conference on. IEEE, 2016.

16.Rahmani, Salem, et al. "A combination of shunt hybrid power filter and thyristor-controlled reactor for power quality." IEEE Transactions on Industrial Electronics 61.5 (2014): 21522164. 